\title{
PENGGUNAAN MEDIA PEMBELAJARAN INTERAKTIF DENGAN APLIKASI ADOBE FLASH CS6 UNTUK MENINGKATKAN MOTIVASI BELAJAR PADA KOMPETENSI DASAR MENGANALISIS PERAN, FUNGSI DAN MANFAAT PAJAK (Studi Kasus Siswa Kelas XI IPS 1 MAN 1 Jember Semester Genap Tahun Ajaran 2016/2017)
}

\author{
Sofiyatul Hidayah ${ }^{1}$, Sri Wahyuni ${ }^{1}$, Hety Mustika Ani ${ }^{1}$ \\ ${ }^{1}$ Program Studi Pendidikan Ekonomi, Fakultas Keguruan dan Ilmu Pendidikan, Universitas Jember
}

\begin{abstract}
This research was a classroom action research (CAR) consists of two cycles. Each cycle consists of planning, action, observation and reflection. The purpose of this study was : (1) described the use of interactive learning media with Adobe Flash CS6 applications in improving students' motivation to the basic competence in analyzing the role, functions and benefits of tax class XI IPS 1 MAN 1 Jember $2^{\text {nd }}$ Semester Of Academic Year $2016 / 2017$, (2) determined the increase motivation to learn class XI IPS 1 Jember through the use of interactive learning media with Adobe Flash CS6 application to the basic competence to analyze the role, functions and benefits of tax in $2^{\text {nd }}$ Semester Of Academic Year 2016/2017. The subjects research were students of class XI IPS 1 MAN 1 Jember which amount 30 students. Source data was gained from teachers and students. Data collection techniques were observation of students' motivation and interview to teachers and students after using the media. Data analysis technique in this study was using descriptive qualitative data analysis. The results showed that: The motivation of students in the first cycle increased to 3.04 in the high category. However, there were indicators of students' motivation in middle category, so we need second cycle. In the second cycle students' motivation rise 3.54 in the high category and all indicators of student motivation were also at a high category. The conclusion of this study was the use of interactive learning media with Adobe Flash CS6 applications can increase students' motivation in class XI IPS 1 MAN 1 Jember on basic competence in analyzing roles, functions and benefits of tax in $2^{\text {nd }}$ semester of academic year 2016/2017.
\end{abstract}

Keywords: Student Learning Motivation, Learning Media, Adobe Flash CS6

\section{PENDAHULUAN}

Pembelajaran yang ideal adalah proses pembelajaran yang melibatkan interaksi antara guru dan siswa pada suatu lingkungan belajar. Interaksi antara guru dan siswa dapat dicontohkan dengan cara siswa menjawab pertanyaan guru didalam kelas. Selain interaksi antara guru dan siswa, pembelajaran yang ideal juga ditandai dengan adanya motivasi belajar yang dimiliki siswa. Motivasi belajar dapat tumbuh dari dalam diri siswa itu sendiri maupun dari luar diri siswa dan tentunya berbeda antara siswa satu dengan yang lainnya. Seorang guru harus bisa memposisikan diri sebagai motivator yakni membantu siswa dalam menumbuhkan motivasi belajarnya. Semakin tinggi motivasi belajar yang dimiliki siswa maka akan semakin besar pula kesuksesan belajarnya.

Guru ekonomi kelas XI IPS di MAN 1 Jember menyatakan bahwa pada saat pembelajaran dikelas, guru sering menghadapi siswa yang tidak memiliki perhatian penuh terhadap materi yang diajarkan seperti sering keluar kelas, mengeluh ketika diberikan tugas oleh guru dan tidak mengerjakan tugas dari guru dengan sungguh - sungguh. Akibatnya siswa tersebut tidak memahami materi yang disampaikan oleh guru.

Adapun hal yang bisa dilakukan guru untuk mengatasi kejadian tersebut adalah dengan memperbaiki proses pembelajaran, seperti memilih media pembelajaran yang sesuai dengan materi, contohnya media pembelajaran interaktif dengan aplikasi Adobe Flash CS6. Dengan adanya media yang baik guru akan mudah menyampaikan materi secara konkrit dan jelas. 
Menurut Akbar (2008:5) Adobe Flash CS6 merupakan salah satu aplikasi pembuatan media pembelajaran interakif yang mudah dan dapat digunakan oleh semua orang. Kelebihan dari Adobe Flash CS6 yaitu memiliki fitur yang banyak sehingga mampu menghubungkan gambar, suara dan animasi secara bersamaan. Selain itu Adobe Flash CS6 juga memiliki fitur yang berektensi tinggi, sehingga media bisa tersimpan dalam handphone agar lebih praktis.

Madcoms (dalam Apriyani, 2012:20) juga mengemukakan bahwa Adobe Flash CS6 adalah software yang baik digunakan untuk mendukung pembelajaran interaktif. Karena, media pembelajaran interaktif dengan aplikasi Adobe Flash CS6 dapat menggabungkan grafis, animasi, suara, serta memiliki kemampuan untuk melakukan interaksi dengan pengguna.

Penelitian terdahulu yang dilakukan oleh Amin (2011) dengan judul "Penggunaan $C D$ Interaktif Dengan Aplikasi Adobe Flash CS6 Dalam Pembelajaran Ekonomi Untuk Meningkatkan Motivasi Belajar dan Hasil Belajar Siswa" membuktikan bahwa dengan menggunakan CD interaktif berbasis multimedia dapat meningkatkan motivasi belajar siswa, dimana sebelum tindakan memiliki skor 2,95 kemudian meningkat menjadi 3,78. Hal tersebut digunakan peneliti untuk melaksanakan penelitian ini supaya mendukung inovasi dalam pelaksanaan pembelajaran.

Kompetensi dasar menganalisis peran, fungsi dan manfaat pajak dalam mata pelajaran ekonomi merupakan materi yang memiliki kajian yang cukup luas. Siswa dituntut untuk mampu menjelaskan konsep-konsep tentang perpajakan dan cara perhitungannya. Oleh karena itu, materi pajak perlu disampaikan dengan media pembelajaran yang menarik agar dapat meningkatkan motivasi belajar siswa. Guru ekonomi kelas XI IPS di MAN 1 Jember sepakat untuk menggunakan media pembelajaran interaktif dengan aplikasi Adobe Flash CS6 untuk mengatasi permasalahan diatas.

Penelitian ini termasuk penelitian tindakan kelas. Tujuan penelitian ini adalah untuk mendeskripsikan penggunaan media pembelajaran interaktif dengan aplikasi Adobe Flash CS6 dalam meningkatkan motivasi belajar siswa kelas XI IPS 1 MAN 1 Jember pada kompetensi dasar menganalisis peran, fungsi dan manfaat pajak semester genap Tahun Pelajaran 2016/2017. Hasil penelitian dari PTK ini diharapkan dapat memberikan manfaat bagi siswa, guru dan penelitian yang sejenis terutama dalam mata pelajaran ekonomi. Adapun manfaat hasil penelitian ini yaitu siswa memiliki motivasi belajar tinggi yang ditunjukkan dengan indikator minat dan perhatian siswa dalam mengikuti pelajaran, semangat siswa dalam mengerjakan tugasnya, tanggung jawab siswa dalam mengerjakan tugasnya, reaksi yang ditunjukkan siswa terhadap stimulus yang diberikan guru dan rasa senang dalam mengerjakan tugas yang diberikan guru.

Berdasarkan latar belakang diatas, maka rumusan masalah dalam penelitian ini yaitu : (1) Bagaimana penggunaan media pembelajaran interaktif dengan aplikasi Adobe Flash CS6 dalam meningkatkan motivasi belajar siswa kelas XI IPS 1 MAN 1 Jember pada kompetensi dasar menganalisis peran, fungsi dan manfaat pajak semester genap tahun pelajaran 2016/2017. (2) Bagaimana peningkatan motivasi belajar siswa kelas XI IPS 1 MAN 1 Jember melalui penggunaan media pembelajaran interaktif dengan aplikasi Adobe Flash CS6 pada kompetensi dasar menganalisis peran, fungsi dan manfaat pajak semester genap tahun pelajaran 2016/2017. 


\section{METODE PENELITIAN}

Penelitian ini dilaksanakan di MAN 1 Jember Jalan Kaliwates No.50, Kabupaten Jember, mulai dari tanggal 27 januari samai dengan 1 Februari 2017. Subyek penelitian adalah siswa kelas XI IPS 1 MAN 1 Jember sebanyak 30 orang. Teknik pengumpulan data dalam penelitian ini berupa obervasi terhadap motivasi belajar siswa dan wawancara kepada guru dan siswa tentang penggunaan media. Indikator keberhasilan penelitian ini yaitu apabila skor rata rata motivasi belajar siswa pada kategori tinggi dengan rentang nilai 3,00-4,00. Prosedur penelitian tindakan kelas ini ini terdiri atas empat kegiatan yang dilakukan dalam siklus berulang. Kegiatan tersebut yaitu: (1) perencanaan, (2) pelaksanaan tindakan, (3) pengamatan, (4) refleksi.

\section{HASIL DAN PEMBAHASAN}

\section{Hasil Penelitian}

Penelitian ini terdiri dari atas siklus I dan siklus II. Pada siklus I guru sudah melakukan kegiatan pembelajaran dengan baik sesuai dengan rencana perbaikan pembelajaran. Namun, masih ada kendala - kendala yang terjadi, seperti : guru yang kurang melaksanakan kegiatan menjelaskan langkah - langkah penggunaan media pembelajaran dan siswa yang ragu - ragu dalam menggunakan media pembelajaran interaktif dengan plikasi Adobe Flash CS6. Hal tersebut terjadi karena media pembelajaran interaktif dengan aplikasi Adobe Flash CS6 ini belum pernah digunakan di kelas XI IPS 1 MAN 1 Jember. Adapun skor motivasi belajar siswa pada siklus I sebagai berikut :

Tabel 1. Motivasi Belajar Siswa Kelas XI IPS 1 MAN 1 Jember Pada Siklus I

\begin{tabular}{|c|l|c|c|c|c|}
\hline No & \multicolumn{1}{|c|}{ Indikator } & $\begin{array}{c}\text { Skor } \\
\text { Pertemuan } \\
\text { I }\end{array}$ & $\begin{array}{c}\text { Skor } \\
\text { Pertemuan } \\
\text { II }\end{array}$ & $\begin{array}{c}\text { Skor } \\
\text { rata - rata }\end{array}$ & Kategori \\
\hline 1. & $\begin{array}{l}\text { Minat dan perhatian siswa } \\
\text { terhadap pelajaran }\end{array}$ & 3,2 & 3,5 & 3,35 & Tinggi \\
\hline 2. & $\begin{array}{l}\text { Semangat siswa dalam } \\
\text { melaksanakan tugasnya }\end{array}$ & 2,3 & 3,2 & 2,75 & Sedang \\
\hline 3. & $\begin{array}{l}\text { Tanggung jawab siswa dalam } \\
\text { mengerjakan tugas tugas } \\
\text { belajarnya }\end{array}$ & 2,3 & 3,3 & 2,8 & Sedang \\
\hline 4. & $\begin{array}{l}\text { Reaksi yang ditunjukkan } \\
\text { siswa terhadap stimulus yang } \\
\text { diberikan guru }\end{array}$ & 3,2 & 3,5 & 3,35 & Tinggi \\
\hline 5. & $\begin{array}{l}\text { Rasa senang yang ditunjukkan } \\
\text { siswa terhadap tugas yang } \\
\text { diberikan guru }\end{array}$ & 2,7 & 3,2 & 2,95 & Sedang \\
\hline Rata - rata motivasi belajar siswa \\
siklus I
\end{tabular}

Sumber : Data primer yang di olah

Tabel 1 Menunjukkan bahwa rata - rata indikator motivasi belajar siswa dalam kategori tinggi. Tetapi, masih ada indikator motivasi belajar siswa yang berada pada kategori sedang. Indikator motivasi belajar siswa yang berada pada kategori sedang yaitu indikator semangat sisa dalam melaksanakan tugasnya, tanggung jawab siswa dalam mengerjakan tugas - tugas 
belajarnya dan indikator rasa senang yang ditunjukkan siswa terhadap tugas yang diberikan guru.

Berdasarkan tabel diatas, guru dan peneliti memutuskan untuk melakukan perbaikan pembelajaran siklus II agar pembelajaran lebih sempurna lagi. Pada siklus II guru lebih memfokuskan pada hal - hal yang belum tercapai pada siklus I, yakni menjadikan indikator motivasi belajar siswa yang sedang menjadi tinggi. Pada siklus II guru lebih sedikit menjelaskan materi dengan metode ceramah dan lebih memfokuskan siswa pada penggunaan media pembelajaran interaktif dengan aplikasi Adobe Flash CS6 agar siswa lebih terbiasa dalam menggunakan media.

Pada siklus II guru sudah melakukan kegiatan pembelajaran dengan baik sesuai dengan rencana perbaikan pembelajaran yang telah diperbaiki demi sempurnanya siklus I. Motivasi belajar siswa pada siklus II meningkat dan semua indikator motivasi belajar siswa siklus II berada pada kategori tinggi. Hal ini terbukti dari antusiasme siswa yang tinggi dalam mengikuti pembelajaran. Guru menyatakan bahwa ia semakin yakin bahwa media pembelajaran interaktif dengan aplikasi Adobe Flash CS6 dapat dijadikan alternative penggunaan media pembelajaran. Berikut ini tabel peningkatan motivasi belajar siswa kelas XI IPS 1 pada siklus II:

Tabel 2. Motivasi belajar siswa kelas XI IPS 1 MAN 1 Jember Pada Siklus i

\begin{tabular}{|l|l|l|l|l|l|}
\hline No & \multicolumn{1}{|c|}{ Indikator } & \multicolumn{1}{|c|}{$\begin{array}{c}\text { Skor } \\
\text { Pertemuan } \\
\text { I }\end{array}$} & $\begin{array}{c}\text { Skor } \\
\text { Pertemuan } \\
\text { II }\end{array}$ & $\begin{array}{c}\text { Skor } \\
\text { Rata-rata }\end{array}$ & Kategori \\
\hline 1. & $\begin{array}{l}\text { Minat dan perhatian siswa } \\
\text { terhadap pelajaran }\end{array}$ & 3,4 & 3,6 & 3,5 & Tinggi \\
\hline 2. & $\begin{array}{l}\text { Semangat siswa dalam } \\
\text { melaksanakan tugasnya }\end{array}$ & 3,4 & 3,5 & 3,45 & Tinggi \\
\hline 3. & $\begin{array}{l}\text { Tanggung jawab siswa dalam } \\
\text { mengerjakan tugas tugas } \\
\text { belajarnya }\end{array}$ & 3,4 & 3,5 & 3,45 & Tinggi \\
\hline 4. & $\begin{array}{l}\text { Reaksi yang ditunjukkan } \\
\text { siswa terhadap stimulus yang } \\
\text { diberikan guru }\end{array}$ & 3,5 & 3,6 & 3,4 & Tinggi \\
\hline 5. & $\begin{array}{l}\text { Rasa senang yang ditunjukkan } \\
\text { siswa terhadap tugas yang } \\
\text { diberikan guru }\end{array}$ & 3,3 & 3,5 & 3,5 & Tinggi \\
\hline $\begin{array}{l}\text { Rata - rata motivasi belajar siswa } \\
\text { siklus II }\end{array}$ & 3,45 & 3,64 & $\mathbf{3 , 5 4}$ & Tinggi \\
\hline
\end{tabular}

Sumber : Data primer yang diolah

Tabel 2 menunjukkan bahwa motivasi belajar siswa pada kategori tinggi yaitu dengan skor 3.54. Semua indikator motivasi belajar siswa juga dalam kategori tinggi berkisar antara 3,3-3,6 dengan skor tertinggi pada indikator minat dan perhatian siswa terhadap pelajaran ekonomi.

Pada siklus II dapat disimpulkan bahwa pembelajaran dengan menggunakan media pembelajaran interaktif dengan aplikasi Adobe Flash CS6 dapat meningkatkan motivasi belajar siswa. Kelima indikator motivasi belajar siswa berada pada kategori tinggi yang meliputi : 
indikator minat dan perhatian siswa terhadap pelajaran, semangat siswa dalam melakukan tugasnya, tanggung jawab siswa dalam mengerjakan tugasnya, reakasi yang ditunjukkan siswa terhda respon yang diberikan guru dan rasa senang yang ditunjukkan siswa terhadap tugas yan diberikan guru. Berdasarkan peningkatan motivasi belajar siswa guru dan peneliti sepakat untuk menghentikan penelitian ini. Berikut ini rekapitulasi peningkatan motivasi belajar siswa dari siklus I ke siklus II :

Tabel 3. Rekapitulasi Peningkatan Motivasi Belajar Siswa

\begin{tabular}{|c|c|c|c|}
\hline No & Siklus & $\begin{array}{c}\text { Skor Motivasi Belajar } \\
\text { Siswa }\end{array}$ & Kriteria \\
\hline 1 & Siklus I & 3,04 & Tinggi \\
\hline 2 & Siklus II & 3,54 & Tinggi \\
\hline \multicolumn{2}{|c|}{ Peningkatan } & $\mathbf{0 , 5}$ \\
\hline
\end{tabular}

Sumber : Data primer yang diolah

Peningkatan Motivasi Belajar Siswa


Gambar 1. Diagram Peningkatan Motivasi Belajar Siswa

Tabel 3 diatas menunjukkan bahwa terjadi peningkatan motivasi belajar siswa dari siklus I dan siklus II. Motivasi belajar pada siklus I sebesar 3,04 dan siklus II 3,47, meningkat 0.5 .

\section{Pembahasan}

Penelitian ini telah memberikan manfaat sendiri bagi guru dan siswa. Bagi guru telah melakukan pembelajaran dengan menggunakan media pembelajaran yang baru yaitu media pembelajaran interaktif dengan aplikasi Adobe Flash CS6. Sedangkan bagi siswa, siswa sudah berdaptasi dengan media baru ini. Sehingga siswa lebih memahami materi yang diberikan secara mandiri.

Hasil penelitian menunjukkan bahwa motivasi belajar siswa pada siklus I tinggi, namun masih ada indikator motivasi belajar siswa yang berada pada kategori sedang, yaitu indikator semangat belajar siswa dalam melaksanakan tugasnya, tanggung jawab siswa dan rasa senag yang ditunjukkan siswa dalam mengerjakan tugas dari guru. Pada siklus I guru dan siswa masih mengalami kendala dalam pengoperasian media. Namun, pada siklus II kegiatan pembelajaran sudah lebih baik. Kendala - kendala yang dialami guru ketika siklus I yaitu guru kurang menjelaskan kepada siswa bagaimana pengguna media pembelajaran yang baru dan kurang 
memotivasi belajar siswa untuk belajar dengan media baru. Sedangkan kendala siswa yaitu siswa masih bingung dalam pengoperasian media.

Mengetahui hasil penelitian siklus I, maka guru berupaya untuk lebih mengoptimalkan proses pembelajaran. Pada siklus II motivasi belajar tinggi dan semua indikator motivasi belajar siswa pada kategori tinggi. Hal tersebut dapat diwujudkan dengan siswa yang tidak meninggalkan kelas sewaktu pelajaran berlangsung, reaksi siswa yang cepat dan tangga ketika mendapat respon dari dan siswa yang memiliki semangat tinggi.

Guru ekonomi mengakui bahwa media pembelajaran interaktif dengan aplikasi Adobe Flash CS6 dapat membantu meningkatkan motivasi belajar siswa dan memudahkan siswa dalam memahami materi serta memecahkan permasalahan yakni tanggung jawab siswa terhadap tugas yang diberikan guru. Disamping itu media ini dipresepsikan sebagai media yang menarik dalam mengajar. Karena, antusias siswa sangat tinggi ketika belajar dengan media ini dan memberikan kesempatan yang luas bagi siswa untuk mengembangkan kemampuan berpikirnya.

Siswa juga mengungkapkan bahwa media pembelajaran interaktif dengan aplikasi Adobe Flash CS6 dapat meningatkan motivasi belajar mereka dan membuat siswa tidak bosan dengan materi yang diajarkan guru. Pernyataan diatas sesuai dengan pendapat Anissa (2016:11) bahwa media pembelajaran dengan aplikasi Adobe Flash CS6 yang dirancang secara menarik akan mampu meningkatkan motivasi belajar siswa, membantu menumbuhkan semangat belajar siswa dan meningkatkan minat siswa untuk belajar.

Murawan (2015:3) juga menyatakan bahwa media pembelajaran interaktif dengan berbasis Adobe Flash CS6 dapat meningkatkan motivasi belajar siswa, terutama untuk materi yang cakupannya luas seperti hitungan, maka lebih disarankan untuk menjadikan Adobe Flash CS6 sebagai alternatif penggunaan media.. Telah diuraikan dalam penelitian ini bahwa kegiatan penelitian dilakukan dengan baik dan mampu menciptakan komunikasi yang baik antara guru dengan siswa dan juga peneliti, sehingga tujuan dari penelitian ini tersampaikan dengan baik

Berdasarkan hasil penelitian,wawancara dengan siswa dan guru serta dukungan teori maka dapat disimpulkan bahwa penggunaan media pembelajaran interaktif dengan aplikasi Adobe Flash dapat meningkatkan motivasi belajar siswa.

\section{KESIMPULAN DAN SARAN}

\section{Kesimpulan}

Berdasarkan hasil penelitian dan pembahasan dapat disimpulkan bahwa melalui penggunaan media pembelajaran interaktif dengan aplikasi Adobe Flash CS6 dapat meningkatkan motivasi belajar siswa kelas XI IPS 1 MAN 1 Jember pada kompetensi dasar menganalisis peran, fungsi dan manfaat pajak Semester Genap Tahun Pelajaran 2016/2017.

\section{Saran}

Berdasarkan hasil penelitian dapat diajukan saran bahwa media pembelajaran interaktif dengan aplikasi Adobe Flash CS6 dapat dijadikan sebagai alternatif penggunaan media pembelajaran yang dapat meningkatkan motivasi belajar siswa terhadap suatu materi pelajaran. 


\section{DAFTAR BACAAN}

Akbar, Amrullah. 2008. Adobe Flash CS6. Yogakarta: Penerbit Andi Yogyakarta.

Amin, Azizah S. 2011. Penggunaan Medai CD Interaktif Pembelajaran Dalam Pembelajaran Ekonomi Untuk Meningkatkan Motivasi dan Hasil Belajar Siswa. (Studi Kasus Siswa Kelas X-6 SMA Muhammadiyah 6 Jember Kompetensi Dasar Konsumsi dan Inverstasi). Skripsi . Universitas Jember. Jawa Timur.

Annisa (2016) Impelementasi Pembelajaran CTL Berbantu Adobe Flash CS6 Untuk Meningkatkan Motivasi Belajar dan Prestasi Belajar Akuntansi (Studi Kasus Siswa kelas X SMK 1 Surakarta). Jurnal Pendidikan Universitas Sebelas Maret

Apriyani, Tri. 2015. Pengembangan Media Pembelajaran Interaktif Adobe Flash CS6 Untuk Meningkatkan Keterampilan Membaca Teks Pendek Bahasa Perancis Siswa Kelas XI SMA El Shadai Magelang. Universitas Negeri Yogyakarta. (32:194)

Djamarah, Syaiful Bahri. 2008. Psikologi Belajar, Jakarta: Rineka Cipta

Murawan. 2015. Perancangan Media Pembelajaran Interaktif Berbasis Adobe Flash CS6 Untuk Meningkatkan Motivasi Belajar Siswa Kelas X SMA Purwakarta. Jurnal Pendidikan Fisika.Universitas Sebelas Maret. 